\title{
Effect of Dexmedetomidine on Intraoperative Haemodynamics and Postoperative Analgesia in Laparoscopic Cholecystectomy
}

\author{
Yojan Trikhatri, ${ }^{1}$ Satyendra Narayan Singh, ${ }^{1}$ Siddhartha Koirala, ${ }^{1}$ Jagat Narayan Prasad, ${ }^{1}$ Sailesh \\ Adhikari $^{2}$ \\ ${ }^{1}$ Department of Anaesthesiology \& Critical Care, ${ }^{2}$ Department of Surgery, BP Koirala Institute of Health \\ Sciences, Dharan, Nepal.
}

\section{Correspondence}

Dr. Yojan Trikhatri, Department of Anaesthesiology \& Critical Care BPKIHS, Dharan, nepal

Email:

yojan_t@yahoo.com

DOI: http://dx.doi.org/10.3126/ jemsn.v14i1.18881

Orcid ID: orcid.org/0000-0002 $-8993-8227$

Article received: Jan $2^{\text {nd }} 2018$ Article accepted: Feb $11^{\text {th }} 2018$

\begin{abstract}
Background \& Objectives: Dexmedetomidine is an $\alpha 2$ agonist with sympatholytic, anxiolytic, sedative and analgesic effect used as adjunct during surgeries for its haemodynamic stabilizing effect and analgesic effect. Primary aims of the study were to evaluate the haemodynamic effect of intravenous dexmedetomidine and the duration and quality of analgesia in laparoscopic cholecystectomy. Secondary aims were sedation levels and occurrence of side effects. Materials \& Methods: Eighty four patients, American society of Anaesthesiologists physical status I and II, aged 18-60 years of either gender undergoing laparoscopic cholecystectomy in general anaesthesia were randomly allocated into two equal groups. Group C patient received Normal Saline and Group S patient received dexmedetomidine loading dose infusion of $1 \mu \mathrm{g} / \mathrm{kg}$ over 10 minutes before induction and maintained with $0.4 \mu \mathrm{g} / \mathrm{kg} / \mathrm{hr}$ till the removal of gall bladder. Induction with propofol and fentanyl was done. Standard monitoring including Heart Rate, Mean arterial pressure, oxygen saturation were monitored perioperatively. Postoperative analgesia requirement and sedation score were assessed. Results: In Group S, the haemodynamic responses were significantly attenuated. During postoperative period, 24 hours analgesic requirement of diclofenac sodium was $141.43 \mathrm{mg}$ in group $\mathrm{S}$ as compared to $217.50 \mathrm{mg}$ in group $\mathrm{C}(\mathrm{p}<0.001)$. Side effects were treatable. Sedation was better in Group S. Conclusion: Dexmedetomidine effectively attenuates haemodynamic stress response during laparoscopic surgery with reduction in postoperative analgesic requirements.
\end{abstract}

Key words: Dexmedetomidine; Haemodynamics; Laparoscopic Cholecystectomy; Postoperative Analgesia

Citation: Trikhatri Y, Singh SN, Koirala S, Prasad JN, Adhikari S. Effect of Dexmedetomidine on Intraoperative Haemodynamics and Postoperative Analgesia in Laparoscopic Cholecystectomy. JCMS Nepal. 2018;14(1):14-20.

\section{INTRODUCTION}

Laparoscopic cholecystectomy is a minimally invasive procedure with reduced morbidity and mortality. Carbon dioxide absorption, positioning, stretched peritoneum and vascular compression leading to pain and haemodynamic instability are the adverse effects of pneumoperitoneum during laparoscopic surgeries.

Dexmedetomidine being a highly selective $\alpha 2$ agonist with $\alpha 1$ to $\alpha 2$ ratio of $1: 1600$ and 8 times more selective than clonidine, ${ }^{1}$ has been used for sedation, analgesia, hemodynamic stability and other purposes. But only a few studies have been conducted to evaluate its effect on perioperative use and the results are also controversial. The side effects are also not well established.

Hence, this study was designed to evaluate the effect of dexmedetomidine in patient haemodynamics, postoperative analgesia, sedation level and occurrence of adverse effects in patients 
undergoing laparoscopic cholecystectomy.

\section{MATERIALS AND METHODS}

This study was a prospective, randomized double blind clinical study and was performed after ethical approval from BPKIHS, Institutional Ethical Review Board (IERB).

Eighty four American Society of Anaesthesiologist physical status (ASA PS) I and II between 18-60 years, of either sex and posted for laparoscopic cholecystectomy under general anaesthesia who gave informed written consent were included in the study. Patients with ASA PS III or more with neurological and psychiatric disorder, known allergy, liver and renal diseases, heart rate (HR) $<60 \mathrm{bpm}$, mean arterial pressure (MAP) $<70 \mathrm{~mm}$ of $\mathrm{Hg}$, duration of laryngoscopy and intubation more than 15 seconds were excluded. The patients were randomly allocated by computer generated random numbers into two groups of 42 each, Group S (patients receiving dexmedetomidine $0.25 \mathrm{ml} / \mathrm{kg}$ $(1 \mu \mathrm{g} / \mathrm{kg})$ intravenously(IV) over 10 minutes before induction then $0.1 \mathrm{ml} / \mathrm{kg} / \mathrm{hr}(0.4 \mu \mathrm{g} / \mathrm{kg} / \mathrm{hr}) \mathrm{IV}$, till removal of gall bladder) and Group $\mathrm{C}$ (patient receiving similar volume of Normal saline).

Infusate was prepared according to the group allotted by anaesthesia assistant not involved in the study. To prepare the infusate, dexmedetomidine $0.5 \mathrm{ml}$ containing $50 \mu \mathrm{g}$ of the drug was withdrawn in a $20 \mathrm{ml}$ syringe and diluted to $12.5 \mathrm{ml}$ with normal saline resulting in the final concentration of $4 \mu \mathrm{g} / \mathrm{ml}$. Similar volume of normal saline infusion by syringe pump was prepared for Group C. The syringe pump was set and covered with a green cloth. Thus, the anaesthesiologist involved in monitoring and the patient were unaware of the group. The data was decoded only at the time of tabulation and analysis. All patients were premedicated with tab alprazolam $0.5 \mathrm{mg}$ on the night before and 2 hours before the surgery. On the operation table, a multiparameter monitor was attached and the baseline HR, MAP, blood pressure and oxygen saturation (SPO2) were noted. 18G Intravenous (IV) cannula was inserted for giving the IV fluids and drugs. Injection granisetron $1 \mathrm{mg}$ was given IV.

10 minutes after starting the drug infusion at $1 \mu \mathrm{g} / \mathrm{kg}$ $(0.25 \mathrm{ml} / \mathrm{kg})$, infusion rate was changed to $0.4 \mu \mathrm{g} / \mathrm{kg}$ / $\mathrm{hr}(0.1 \mathrm{ml} / \mathrm{kg} / \mathrm{hr})$ and preoxygenation was performed for 3 minutes. Patients were induced with fentanyl $1.5 \mu \mathrm{g} / \mathrm{kg}$, IV propofol till the loss of verbal command, followed by $0.1 \mathrm{mg} / \mathrm{kg}$ of injection vercuronium bromide and trachea was intubated. Anaesthesia was maintained with isoflurane in oxygen. Intra-abdominal pressure was maintained between 12 to $14 \mathrm{~mm} \mathrm{Hg}$. End tidal carbon dioxide was kept between 35 to $45 \mathrm{~mm} \mathrm{Hg}$. Injection $0.25 \%$ plain bupivacaine $20 \mathrm{ml}$ intraperitoneal and $10 \mathrm{ml}$ skin infiltration was given in all the patients. Conventional way of reversal and extubation were followed.

HR, systolic blood pressure(SBP), diastolic blood pressure(DBP), MAP and $\mathrm{SpO} 2$ were recorded before induction, one minute after intubation, two minutes, five minutes and every five minutes thereafter till the end of surgery and 5, 10, 20 and 30 mins postoperatively. Patients were also observed for postoperative sedation level, effective analgesia (time from completion of surgery to the first dose of rescue analgesia, when $\mathrm{VAS}>4$ [visual analogue scale]), total amount of analgesic drug required during the first 24 hours postoperatively and the adverse effects. Injection diclofenac sodium $75 \mathrm{mg}$ IM was given if VAS 4 to 6 and injection tramadol 50mg IV if VAS score $>6$.

Degree of sedation was assessed using Ramsay Sedation Score at $45 \mathrm{mins}$, 60mins and every 30 minutes till $300 \mathrm{mins}$, postoperatively or till the patient was awake and conscious.

Throughout the study, patients were observed for any adverse effects like bradycardia, tachycardia (fall of heart rate less than or more than $20 \%$ from the base line, respectively), hyper or hypotension (MAP more than or less than $20 \%$ of preoperative level, respectively) or any other complication and managed accordingly.

According to an article, ${ }^{2} \mathrm{P} 1=0.05$ and $\mathrm{P} 2=0.35$ (where P1 and P2 is the proportion of tachycardia in Normal saline group and intravenous Dex 0.2 group respectively). Using the two sample proportion test, $95 \% \mathrm{CI}$ and $90 \%$ Power, the resulted sample size was 36 in each arm. We included 42 patients in each group to allow for dropouts.

The collected data were entered in MS Excel 2007 and converted into SPSS software version 20.0 for statistical analysis. For descriptive statistics mean, standard deviation, proportion percentage was calculated. For inferential statistics chi square test, Independent $\mathrm{T}$ test or Mann-Whitney U- Test was applied to find out the significant difference between Group $\mathrm{S}$ and Group $\mathrm{C}$ with other related variable at $95 \% \mathrm{CI}$ where $\mathrm{p}=0.05$.

\section{RESULTS}

Demographic variables, duration of surgery and anaesthesia between the two groups were comparable (Table 1). 
Baseline HR and MAP were comparable in both the groups. Mean HR was significantly lower in Group $\mathrm{S}$ than Group $\mathrm{C}$ at most of the times of observation, intraoperatively (Figure 1). Mean MAP was significantly lower in Group $\mathrm{S}$ at 25, 30 and 55 minutes intervals, intraoperatively (Figure 2).

Effective analgesia (time from completion of surgery to first dose of rescue analgesia, VAS $>4$ ) or the time of first rescue analgesia was significantly earlier in Group C than in Group S (Table 2).Total analgesia requirement in 24 hours was higher in Group C than Group S (Table 3). Although total tramadol requirement was comparable in both groups but diclofenac sodium requirement was significantly $(\mathrm{P}<0.001)$ higher in Group $\mathrm{C}$.

In Group S, 25 patients as compared to 38 patients in Group C, were co-operative, oriented and calm, at 30mins after surgery (Figure 3). In Group S, 17 patients as compared to 4 patients in Group C, were responsive to commands only, at 30 mins after

Table 1: Demographic parameters and duration of surgery and anaesthesia.

\begin{tabular}{|c|c|c|c|}
\hline Characteristics & GROUP S(n=42) & GROUP C $(n=42)$ & P VALUE \\
\hline $\begin{array}{l}\text { Age in years } \\
\text { (mean } \pm S D \text { and range) }\end{array}$ & $34.76 \pm 11.70(18-60)$ & $36.93 \pm 12.84(18-60)$ & 0.426 \\
\hline \multicolumn{4}{|l|}{ Gender } \\
\hline Male & $11(26.19 \%)$ & $16(38.10 \%)$ & 0.243 \\
\hline Female & $31(73.81 \%)$ & $26(61.90 \%)$ & \\
\hline $\begin{array}{l}\text { Weight in } \mathrm{Kg} \\
\text { (mean } \pm S D \text { and range) }\end{array}$ & $57.67 \pm 11.34(36-80)$ & $60.31 \pm 13.57(36-100)$ & 0.336 \\
\hline \multicolumn{4}{|l|}{ ASA PS } \\
\hline 1 & $31(73.80 \%)$ & $34(81.00 \%)$ & 0.434 \\
\hline 2 & $11(26.20 \%)$ & $8(19.00 \%)$ & \\
\hline $\begin{array}{l}\text { Duration of anaesthesia } \\
\text { (in min) }\end{array}$ & $69.40 \pm 20.13$ & $66.07 \pm 11.71$ & 0.356 \\
\hline $\begin{array}{l}\text { Duration of surgery } \\
\text { (in min) }\end{array}$ & $49.52 \pm 20.94$ & $46.31 \pm 8.487$ & 0.359 \\
\hline
\end{tabular}

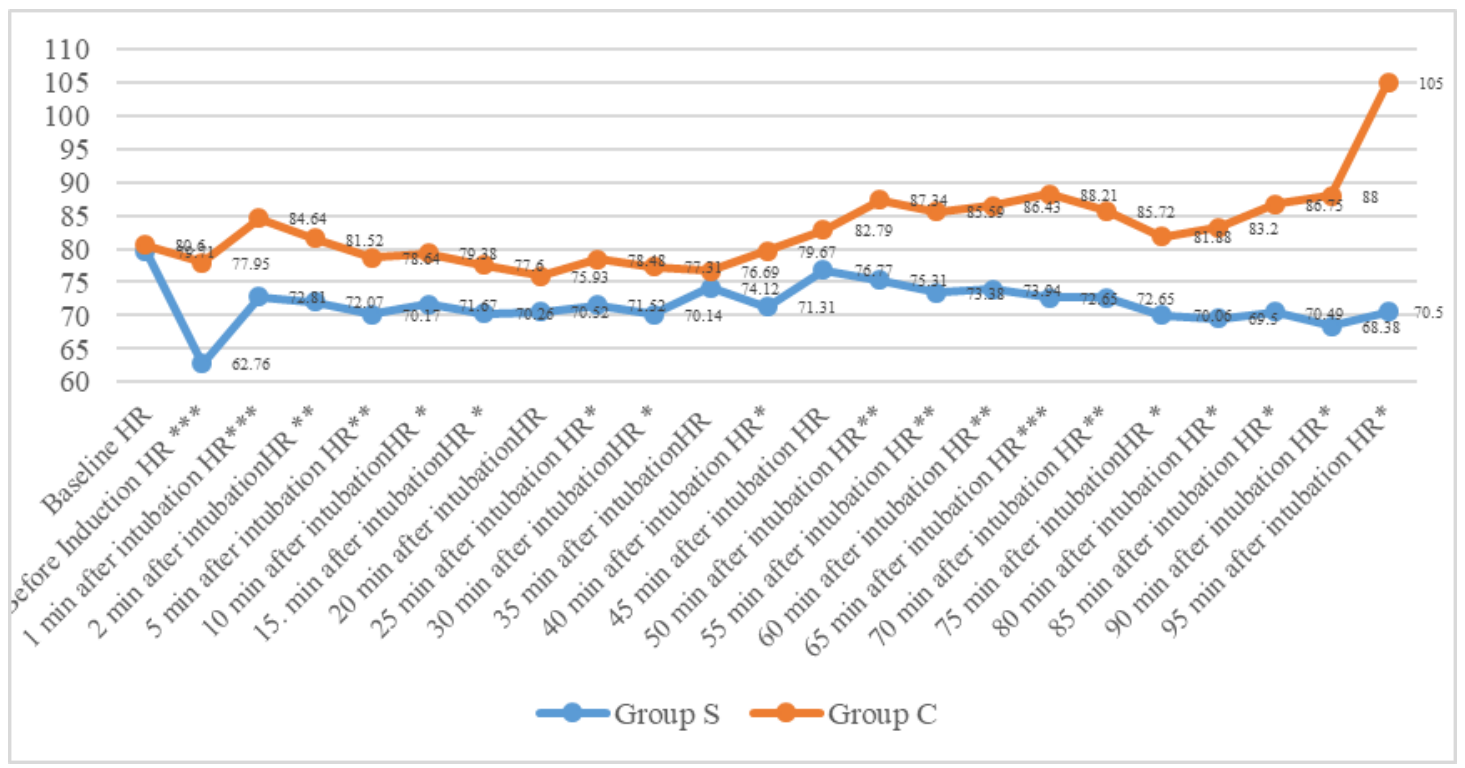

Figure 1: Heart rate between two groups at different intervals 


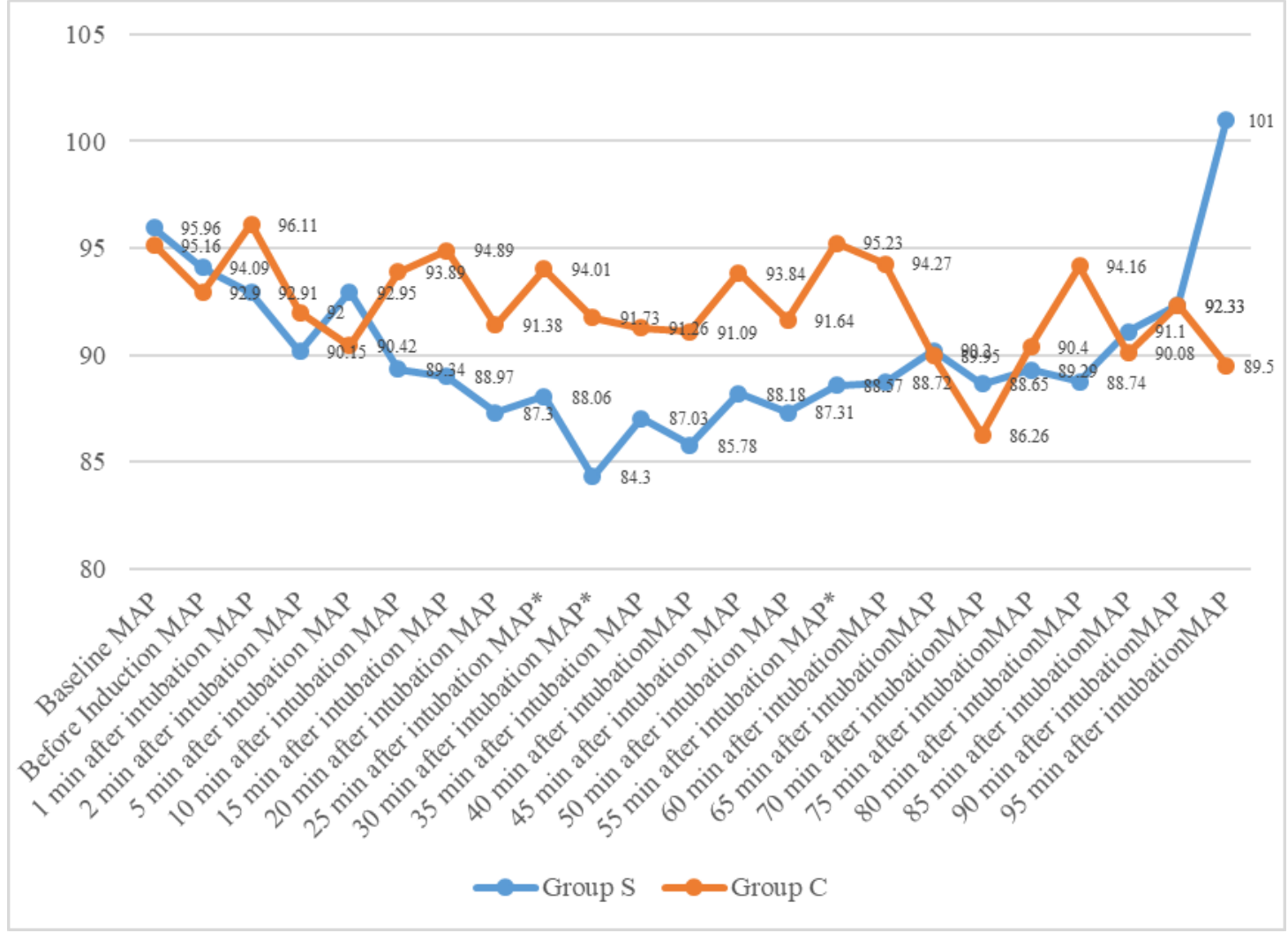

Figure 2: Mean arterial pressure between two groups at different intervals

Table 2: Postoperative analgesia requirement

\begin{tabular}{lccc}
\multicolumn{1}{c}{ Parameter } & $\begin{array}{c}\text { Group S } \\
\text { Median (IQR) }\end{array}$ & $\begin{array}{c}\text { Group C } \\
\text { Median (IQR) }\end{array}$ & P value \\
$\begin{array}{l}\text { Time of the first rescue analgesia } \\
\text { (minutes) }\end{array}$ & $42.5(25-50)$ & $20(15-30)$ & $<0.001$
\end{tabular}

Table 3 Comparison of analgesia required in $\mathbf{2 4}$ hours in both the groups

\begin{tabular}{|lccc}
\multicolumn{1}{c}{ Parameters } & \multicolumn{2}{c}{ Dose in milligrams } & \\
& Group S & Group C & P value \\
Tramadol & $54.29 \pm 14.20$ & $50.00 \pm 0.00$ & 0.08 \\
\hline Diclofenac & $141.43 \pm 65.0$ & $217.50 \pm 60.76$ & $<0.001$
\end{tabular}

surgery. In Group S, 11 patients as compared to 4 patients in Group C were co-operative, oriented and calm, at 45 mins after surgery (figure 3). In Group S, 7 patients were responsive to commands only whereas in Group C, no patients were responsive to commands only, at 45 mins after surgery. All patients in both the groups became fully awake and conscious at 60 mins. So, further scores were not taken.

14 cases developed hypertension in Group S and 18 in Group C. Hypotension developed in 5 patients in Group $\mathrm{S}$ and none in Group C. Occurrence of tachycardia was 10 and 22 in Group S and Group C, respectively. There were 13 cases of bradycardia in Group $\mathrm{S}$ whereas 2 in Group C. One of the patient in Group $\mathrm{S}$ developed bronchospasm just before extubation.

\section{DISCUSSION}

Laparoscopic cholecystectomy is well established with benefits including reduced postoperative pain, improved cosmetic results, patient satisfaction, and reduced hospital stays.

Pneumoperitonium is produced by administration of carbondioxide (CO2) during laparoscopic 


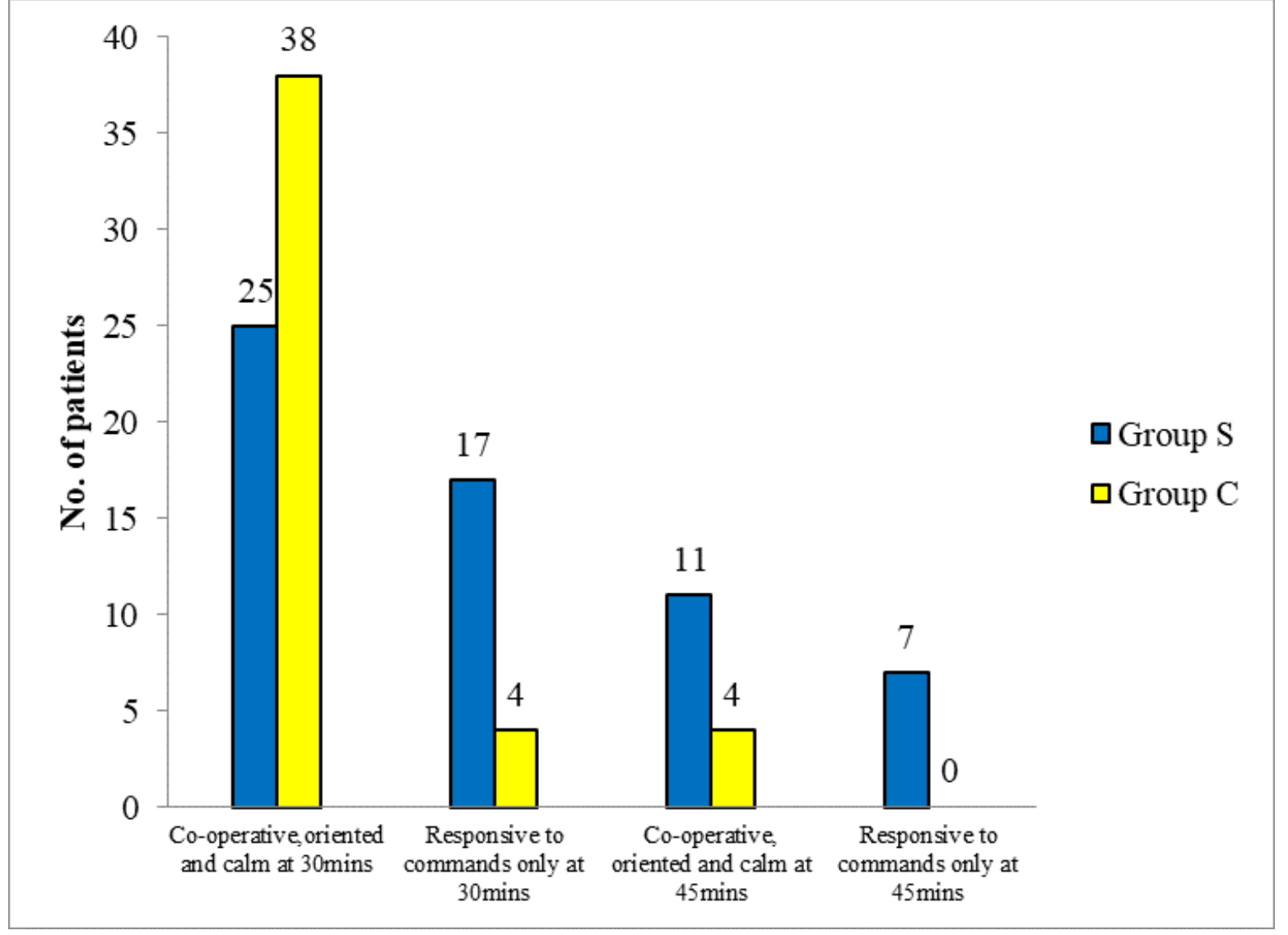

Figure 3: Sedation score between the two groups

surgical procedures. ${ }^{3,4}$ Both pneumoperitoneum and $\mathrm{CO} 2$ causes adverse cardiovascular effects. ${ }^{5}$ Some of these effects are related to increased intraabdominal pressure. Immediately, after pneumoperitonium, plasma level of norepinephrine, epinephrine and plasma renin activity increases. ${ }^{6}$ The renin-angiotensin-aldosterone-system is also activated by the increased catecholamine level. Altogether contributing to elevated arterial pressure, increased systemic and pulmonary vascular resistance and reduced cardiac output. ${ }^{7}$

Recently, there is increase in the use of $\alpha 2$ agonist in anaesthesia practice because of their anxiolytic, sedative, sympatholytic and analgesic sparing properties. $^{8}$

Dexmedetomidine is a highly selective $\alpha 2$ adrenergic agonist. It acts through three types of $\alpha 2$ receptors- $\alpha 2 \mathrm{~A}, \alpha 2 \mathrm{~B}$ and $\alpha 2 \mathrm{C}$ situated in brain and spinal cord. The action includes sedation, anxiolysis, analgesia and sympatholysis, the latter leading to hypotension and bradycardia. Activation of $\alpha 2 \mathrm{~A}$ receptors in brain stem vasomotor centre results in suppression of norepinephrine release and causes hypotension and bradycardia. Stimulation of $\alpha 2 \mathrm{~A}$ and $\alpha 2 \mathrm{C}$ in locus ceruleus causes sedation. In the spinal cord, activation of both $\alpha 2 \mathrm{~A}$ and $\alpha 2 \mathrm{C}$ receptors directly reduce pain transmission by reducing release of substance $P$.

Considering these properties, many researches are performed to assess its effect on haemodynamics in patients undergoing laparoscopic surgeries.

With higher dose infusion of dexmedetomidine , high incidence of adverse cardiac effects have been observed. ${ }^{9}$ In low dose, dexmedetomidine exhibits linear kinetics, meaning that a constant amount of drug is eliminated per hour rather than a constant fraction of drug.

Hence in the current study, we used low dose of $0.4 \mu \mathrm{g} / \mathrm{kg} / \mathrm{hr}$ dexmedetomidine infusion after a loading dose of $1 \mu \mathrm{g} / \mathrm{kg}$ over 10 minutes.

In our study, after dexmedetomidine infusion of loading dose of $1 \mu \mathrm{g} / \mathrm{kg}$, HR decreased significantly from the baseline. There were no changes in HR and MAP in the normal saline group. Activation of $\alpha 2$ adrenoceptors on vascular smooth muscle is thought to result in vasoconstriction, increased blood pressure and probable reflex decreased heart rate. ${ }^{10}$ In our study, there was decrease in both the heart rate and blood pressure during the bolus infusions, however, the decrease in MAP was not 
significant. This suggests that initial $1 \mu \mathrm{g} / \mathrm{kg}$ loading infusion for 10mins is not rapid and may cause minimal increase in blood concentrations of dexmedetomidine. This finding is similar to other studies. ${ }^{2,11}$ In contrast to our study, in a study, ${ }^{12}$ there was no difference in baseline and before induction value of $\mathrm{HR}$. The reason could be because of lower dose $(0.2 \mu \mathrm{g} / \mathrm{kg} / \mathrm{hr})$ of dexmedetomidine infusion used, as compared to our study.

In our study, all tracheal intubation were performed by the same anaesthesiologist. There was significant decrease in HR (8.65\%) from baseline to one minute after intubation values in dexmedetomidine group. There was no significant difference in MAP in dexmedetomidine group. The use of intraoperative demedetomidine may increase hemodynamic stability because of attenuation of the stress induced sympathoadrenal responses to intubation and during surgery. ${ }^{13}$ This finding was also seen in a study, ${ }^{12}$ in which at $1 \mathrm{~min}$ postintubation, the MAP and HR decreased significantly in dexmedetomidine group, $14 \%$ and $3 \%$ respectively. In a study, ${ }^{2}$ at $1 \mathrm{~min}$ after intubation, there was significant fall in MAP $(5.76 \%)$ and $\mathrm{HR}(3.96 \%)$ in dexmedetomidine group $(0.4 \mu \mathrm{g} / \mathrm{kg} / \mathrm{hr})$ but in contrast to our study, there was significant rise in $\mathrm{MAP}(4.58 \%)$ and $\mathrm{HR}$ $(8.05 \%)$ in other dexmedetomidine group $(0.2 \mu \mathrm{g} /$ $\mathrm{kg} / \mathrm{hr}$ ). The reason may be due to low dose of dexmedetomidine. In a similar study, ${ }^{14}$ the heart rate and mean blood pressure were found to be low in dexmedetomidine group as compared to normal saline group which was statistically significant after laryngoscopy and intubation. In our study, there were no significant changes in HR and MAP in normal saline group. In a study, ${ }^{2}$ contrast to our study, the normal saline group showed significant increase in $\operatorname{HR}(19.71 \%)$ and $\operatorname{MAP}(15.04 \%)$ from the baseline. The reason may be due to use of glycopyrrolate $5 \mu \mathrm{g} / \mathrm{kg}$ IM 45 mins before induction time. In our study, HR and MAP was found to be decreased in dexmedetomidine group at almost all the intervals compared to NS group (but only change in HR was statistically significant) which was validated by the findings of some other studies. ${ }^{2,11,12,14}$

The adverse effects were seen more with dexmedetomidine, however, they were treatable. One case of bronchospasm occurred just before the extubation probably due to light plane of anaesthesia.
Recent studies, not surprisingly, show that intraoperative dexmedetomidine (bolus dose of 0.5$1 \mu \mathrm{g} / \mathrm{kg}$, with or without continuous infusion of 0.5 $2 \mu \mathrm{g} / \mathrm{kg} / \mathrm{hr}$ ) causes a significant reduction in the need for both intraoperative and postoperative analgesics in adults. ${ }^{15}$ In our study, the pain perception was early in normal saline, postoperatively. Similar inference was made, ${ }^{2}$ but the rescue analgesia in dexmedetomidine $(0.4 \mu \mathrm{g} / \mathrm{kg} /$ hr) group was at 249 mins. This may be because they used inj. tramadol $1 \mathrm{mg} / \mathrm{kg} \quad \mathrm{IM}$ as premedication. Overall, analgesic requirement in dexmedetomidine group was less than normal saline group. Even if the elimination half -life of dexmedetomidine is short (2-3hrs), the analgesic sparing effect observed after a preoperative or an intraoperative administration usually lasts up to 24 hours , with the anxiolytic, sedative, and thymoanaleptic properties implicated as being partly responsible for this effect. ${ }^{16,17}$

Patients were found significantly sedated among dexmedetomidine group than normal saline group in 30mins in our study but all the patient were cooperative, oriented and calm after 45mins postoperatively. There was better sedation in patients involved in dexmedetomidine $(0.4 \mu \mathrm{g} / \mathrm{kg} / \mathrm{hr}$ and $0.2 \mu \mathrm{g} / \mathrm{kg} / \mathrm{hr}$ ) than in normal saline group in a study, ${ }^{2}$ which was similar to our findings.

\section{CONCLUSION}

Our study has shown that, dexmedetomidine blunts haemodynamic response to laryngoscopy and tracheal intubation as well as it also improves intraoperative haemodynamic stability, causes postoperative sedation and decreases analgesic requirement. However the sample size was calculated based on heart rate so the power of this study might not be adequate for all primary endpoints which is the limitation of this study.

\section{Funding}

None

\section{Conflict of Interest Statement:}

None Declared

\section{REFERENCES}

1. Virtanen R, Savola JM, Saano V, Nyman L. Characterization of the selectivity, specificity and potency of medetomidine as an alpha 2-adrenoceptor agonist. Eur J Pharmacol. https://doi.org/10.1016/0014-2999(88)90744-3

2. Manne G, Upadhyay M, Swadia V. Effects of low dose dexmedetomidine infusion on haemodynamic stress response, sedation and post-operative analgesia requirement in patients undergoing laparoscopic cholecystectomy. Indian J Anaesth. 2014;58(6):726. 
https://doi.org/10.4103/0019-5049.147164.

25624537.

3. Hodgson C, McClelland R, Newton J. Some effects of the peritoneal insufflation of carbon dioxide at laparoscopy. Anaesthesia.

https://doi.org/10.1111/j.1365-2044.1970.tb00226.x

4. Blobner M, Felber AR, Gögler S, Feussner H, Weigl EM, Jelen $\mathrm{G}$, et al. The resorption of carbon dioxide from the pneumoperitoneum in laparoscopic cholecystectomy. Anaesthesist. 1993

May;42(5):288-94. PMID : 8317685.

5. Richardson JD, Trinkle JK. Hemodynamic and respiratory alterations with increased intra-abdominal pressure. J Surg Res.

https://doi.org/10.1016/0022-4804(76)90112-8.

6. Joris JL, Noirot DP, Legrand MJ, Jacquet NJ, Lamy ML. Hemodynamic changes during laparoscopic cholecystectomy. Anesth Analg. 1993;76:1067-71. https://doi.org/10.1213/00000539-199305000-00027. PMID: 8484509.

7. Lenz RJ, Thomas TA, Wilkins DG. Cardiovascular changes during laparoscopy. Studies of stroke volume and cardiac output using impedance cardiography. Anaesthesia 1976;31(1):4-12. 2044.1976.tb11738.x. PMID: 130811.

8. Khan ZP, Munday IT, Jones RM, Thornton C, Mant TG, Amin D. Effects of dexmedetomidine on isoflurane requirements in healthy volunteers. Br J Anaesth. 1999 Sep;83(3):372-80. https://doi.org/10.1093/bja/83.3.372. PMID: 10655905.

9. Tufanogullari B, White PF, Peixoto MP, Kianpour D, Lacour T, Griffin J, et al. Dexmedetomidine infusion during laparoscopic bariatric surgery: The effect on recovery outcome variables. Anesth Analg. 2008;106:1741 -8 . https://doi.org/10.1213/ane.0b013e318172c47c PMID: 18499604

10. Bloor BC, Ward DS, Belleville JP, Maze M. Effects of intravenous dexmedetomidine in humans. II. Hemodynamic changes. Anesthesiology. 1992 Dec;77 (6):1134-42. https://doi.org/10.1097/00000542-19921200000014. PMID: 1361311.

11. Nofal WH, El-alim AAA, Eissa DE. Evaluation of the effects of dexmedetomidine on perioperative hemodynamic changes, analgesic requirements, and recovery profile during laparoscopic cholecystectomy. Ain-Shams Anaesthesiol. 2013;6(1):44-9.

12. Bhattacharjee DP, Nayek SK, Dawn S, Bandopadhyay G, Gupta K. Effects of dexmedetomidine on haemodynamics in patients undergoing laparoscopic cholecystectomy- A comparative study. J Clin Anaesth. 2010;26(1):45-8.

13. Scheinin B, Lindgren L, Randell T, Scheinin H, Scheinin M. Dexmedetomidine attenuates sympathoadrenal responses to tracheal intubation and reduces the need for thiopentone and peroperative fentanyl. Br J Anaesth. 1992 Feb;68(2):126-31. https://doi.org/10.1093/bja/68.2.126. PMID: 1347229.

14. Bhanderi D, Shah C, Shah B, Mandowara N. Comparision of IV Dexmedetomidine V/S IV Clonidine in Hemodynamic Stability in Laparoscopic Surgery. Res J Pharm, Biol Chem Sci. 2014;5(910):910-7.

15. Massad IM, Mohsen WA, Basha AS, Al-Zaben KR, AlMustafa MM, Alghanem SM. A balanced anesthesia with dexmedetomidine decreases postoperative nausea and vomiting after laparoscopic surgery. Saudi Med J. 2009;30:1537-41. PMID: 19936416.

16. Al-Zaben KR, Qudaisat IY, Al-Ghanem SM, Massad IM, Al-Mustafa MM, Al-Oweidi AS, et al. Intraoperative administration of dexmedetomidine reduces the analgesic requirements for children undergoing hypospadius surgery. Eur J Anaesthesiol. 2010;27:247-52. https://doi.org/10.1097/EJA.0b013e32833522bf. PMID: 19952754.

17. Unlugenc H, Gunduz M, Guler T, Yagmur O, Isik G. The effect of pre-anaesthetic administration of intravenous dexmedetomidine on postoperative pain in patients receiving patient-controlled morphine. Eur J Anaesthesiol. 2005 May;22(5):386-91. https://doi.org/10.1017/S0265021505000669. PMID: 15918389 . 